Inflation Risk Premia and Survey Evidence on Macroeconomic Uncertainty

Paul Söderlind

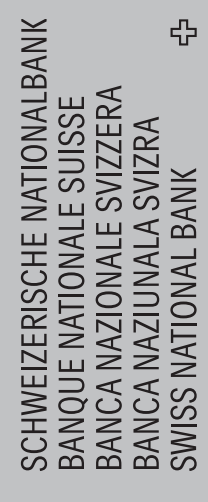

U

(a)

(1)

ro

?

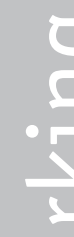

年的的

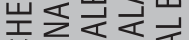

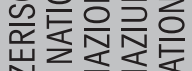

논리

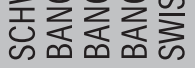


The views expressed in this paper are those of the author(s) and do not necessarily represent those of the Swiss National Bank. Working Papers describe research in progress. Their aim is to elicit comments and to further debate.

ISSN 1660-7716 (printed version)

ISSN 1660-7724 (online version)

๑ 2009 by Swiss National Bank, Börsenstrasse 15, P.0. Box, CH-8022 Zurich 


\title{
Inflation Risk Premia and Survey Evidence on Macroeconomic Uncertainty
}

\author{
Paul Söderlind* \\ 29 January 2009 (First draft: 19 June 2008)
}

\begin{abstract}
Nominal and real U.S. interest rates (1997Q1-2008Q2) are combined with inflation expectations from the Survey of Professional Forecasters to calculate time series of risk premia. It is shown that survey data on inflation and output growth uncertainty, as well as a proxy for liquidity premia can explain a large amount of the variation in these risk premia.
\end{abstract}

Keywords: break-even inflation, liquidity premium, Survey of Professional Forecasters.

JEL Classification: E27, E47.

*University of St. Gallen and CEPR. Address: SBF, University of St. Gallen, Rosenbergstrasse 52, CH-9000 St. Gallen, Switzerland. E-mail: Paul.Soderlind@unisg.ch. I thank Michael Fisher and Angelo Ranaldo for comments; Juan Angel García and Andrés Manzanares for fruitful discussions at an early stage of this work. 


\section{Introduction}

The idea of this paper is very simple. Data on nominal and real (inflation indexed) interest rates is combined with survey data on inflation expectations to construct a quarterly time series of "total premium" (inflation risk premium plus the difference between nominal and real liquidity premia) for the sample 1997Q1-2008Q2. This time series is then regressed on proxies for liquidity premia and measures of inflation and output uncertainty (from survey data on probability distributions). The results indicate that the regressors are significant and explain a considerable fraction of the movements of the total premium.

Several studies have made use of real interest rates, liquidity premia or survey data, but very few (if any) have combined them to have data on all the key ingredients of a modern Fisher equation.

Reschreither (2004), Chen, Liu, and Cheng (2005) and D'Amico, Kim, and Wei (2008) use nominal and real interest rates to estimate no-arbitrage yield curve models with latent (unobservable) factors. The current paper instead estimates a simple yield curve model using only observable factors that measure beliefs of economic agents: survey measures of inflation and output uncertainty and disagreement. It is potentially very important to have direct measures of subjective market beliefs-since it allows us to separate the issue of the economic theory about the inflation risk premium from that of rational expectations/small sample problems. A particular strength of the survey data used in the current paper is that it allows us to calculate explicit measures of both uncertainty and disagreement.

Lahiri, Teigland, and Zaporowski (1988) and García and Manzanares (2007) also use survey data to estimate inflation uncertainty (and even skewness/kurtosis). The former paper does not find any effect of uncertainty on nominal interest rates (on the sample 1969-1986), but García and Manzanares (2007) find that it is important for understanding the inflation scares during the Volcker period in the early 1980s. The current paper differs from these earlier contributions in many details (in particular, on how to estimate uncertainty from survey data), but more importantly by focusing on the period when real (inflation indexed) interest rates are available (since 1997Q1). This allows for controlling for one potentially important driving force of nominal rates.

Carlstrom and Fuerst (2004) and Shen (2006) compare the "break-even inflation rate" (the difference between the nominal and real yields) to survey measures of inflation ex- 
pectations. They argue that the break-even inflation rates are too low-due to a considerable liquidity premium in the observed real rates. The current paper incorporates those results - and goes on to study if other factors (inflation and output uncertainty/disagreement) add explanatory value.

The outline of the paper is as follows. Section 2 derives a modern Fisher equation; section 3 discusses the data and the estimation approach; section 4 presents the empirical results and section 5 concludes.

\section{The Fisher Equation}

This section presents the theoretical foundation of my empirical approach. A utility function with constant relative risk aversion gives the following first order condition for an investor's investment in a nominal bond with interest rate $i$

$$
1=\beta \operatorname{Eexp}(i-\pi-\gamma \Delta c)
$$

where $\beta$ is the time discount rate, $\mathrm{E}$ the (conditional) expectation, $\pi$ the inflation rate, $\gamma$ the risk aversion and $\Delta c$ the consumption growth. Notice that $i-\pi$ is the real return on the bond. To simplify the notation, time subscripts are suppressed. The first order condition for a real bond (without liquidity risk) is similar: substitute the real interest rate on a real bond without liquidity risk $(\tilde{r})$ for $i-\pi$.

If $i-\pi-\gamma \Delta c$ has a normal distribution, then the first order conditions for a nominal and a real bond (without liquidity risk) can be combined to write the inflation risk premium as

$$
i-\tilde{r}-\mathrm{E} \pi=-\gamma \operatorname{Cov}(\pi, \Delta c)-\operatorname{Var}(\pi) / 2,
$$

where $\mathrm{E} \pi$ is expected inflation, $\operatorname{Cov}()$ denotes a covariance and $\operatorname{Var}()$ a variance. This expression shows that the inflation risk premium on a nominal bond equals a covariance term plus a Jensen's inequality term. A negative covariance between inflation and consumption makes a nominal bond risky (since it has a low real return when consumption is low), so investors ask for a risk premium. The moments in (2) are conditional and possibly time-varying.

The real (inflation indexed) bonds have occasionally been somewhat illiquid assets and it is often argued that they carry a liquidity premium (for instance, see Shen (2006)). 
Let $r$ indicate the real interest rate observed in data and let $L P R$ indicate the real liquidity premium. Clearly, $r=\tilde{r}+L P R$, so the Fisher equation can (after dropping the Jensen's inequality term) be written

$$
i-r-\mathrm{E} \pi=\underbrace{-\gamma \operatorname{Cov}(\pi, \Delta c)}_{\text {inflation risk premium }}-L P R .
$$

The "total premium" $(i-r-\mathrm{E} \pi)$ depends positively on the inflation risk premium captured by the first term and negatively on the liquidity premium on real bonds. (To be more precise, $L P R$ can be interpreted as the difference between the liquidity premia on nominal and real bonds.)

Central banks often calculate a "break-even inflation" as the difference between nominal and real yields $(i-r)$-with the purpose of approximating the market's inflation expectation. If the inflation risk premium and the liquidity premium in the Fisher equation (3) are constant, then the break-even inflation differs from the inflation expectations by a constant: changes in the break-even inflation are then precise measures of changes in inflation expectations. Otherwise, an increased inflation risk premium increases the break-even inflation rate, while an increased real liquidity premium decreases it-and these movements may hurt the informational value of the break-even inflation.

The plan of this paper is to find proxies for the inflation risk premium and the real liquidity premium - in order to understand the pricing of bonds and to improve upon the practice of calculating the break-even inflation rate.

\section{Data and Relation to the Fisher Equation}

This section describes the data and how it is used to construct proxies for macroeconomic uncertainty and liquidity premia.

\subsection{Data}

I use McCulloch's (2008) end of month estimates of nominal and real zero coupon rates, quarterly data on subjective beliefs from the Survey of Professional Forecasters (SPF) at the Federal Reserve Bank of Philadelphia (2008) and the daily proxy for the liquidity premium from the Federal Reserve Bank of Cleveland (2008). The effective sample is quarterly and covers the period 1997Q1-2008Q2: the starting point is due to the intro- 
duction of the TIPS (Treasury Inflation-Protected Securities) in 1997Q1 and the end point to the discontinuation of the liquidity premium data in autumn 2008 (see below).

The SPF is a quarterly survey of forecasters' views on key economic variables. The respondents, who supply anonymous answers, are professional forecasters from the business and financial community. The survey is since 1991 administered by the Federal Reserve Bank of Philadelphia (see Croushore (1993) for details). It asks for point forecasts of many macroeconomic and financial variables, but also for probability distributions (histograms) of real output growth and GDP deflator inflation. The deadline for the survey is approximately in the middle of the quarter.

The survey data from the SPF is very interesting, but far from perfect for investigating the empirical relevance of the (modern) Fisher equation. It is therefore necessary to discuss the compromises that need to be made.

The Fisher equation (2) applies to an individual investor: it is his/her first order condition. However, the survey asks about macroeconomic aggregates, not the respondent's own consumption - and the forecasters in the SPF do not agree (especially not about the point forecasts). A solution to this problem is found in the asset pricing literature on heterogenous beliefs: it suggests that the difference between (planned) individual and aggregate consumption is a function of the disagreement between investors. ${ }^{1}$ For this reason, measures of disagreement about the point forecasts of inflation and real growth will be included in the empirical analysis. Another reason for including disagreement is that it is often thought of as an alternative proxy for uncertainty.

The survey data has a number code for each respondent, so it is possible to estimate the Fisher equation on individual data. ${ }^{2}$ However, there are several problems with that approach - in particular with how to handle outliers and other strange data points (discussed below). Instead, I estimate a Fisher equation on cross-sectional averages (trimmed means or medians) of all the terms. This is a valid way of doing it, since the first order condition (using disagreement to proxy for the difference between individual and aggregate consumption) should hold for each investor-and therefore for an average. It might sacrifice a bit of econometric efficiency, but makes it easier to handle outliers.

The SPF contains only univariate distributions, and hence no information about the covariance of inflation and consumption that enters (3). I therefore approximate the co-

\footnotetext{
${ }^{1}$ See, for instance, Anderson, Ghysel, and Juergens (2005), David (2008) and Söderlind (2008).

${ }^{2}$ This gives a dynamic panel regression since the participants enter and leave the survey at different times.
} 

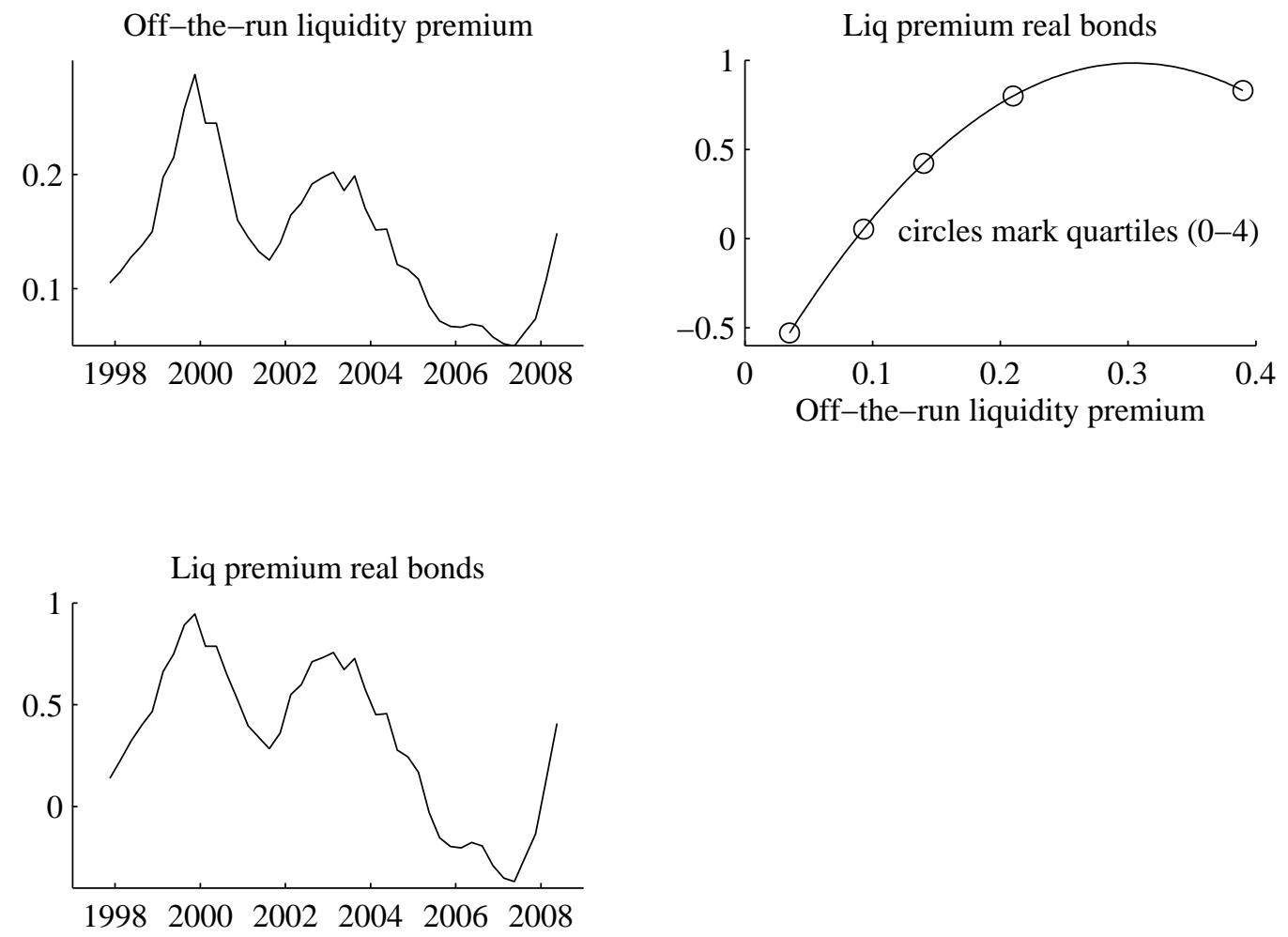

Figure 1: Liquidity premium according to the Federal Reserve Bank of Cleveland (2008). This figure shows a 4-quarter moving average of the liquidity premium on off-the-run nominal bonds, the functional form of equation (4) and the resulting liquidity premium on real bonds.

variance by a linear combination of the two standard deviations. One possible interpretation is that this is a Taylor series expansion.

To analyse long-term interest rates, we ought to have data on long-run uncertainty. Unfortunately, the SPF asks only for short-run uncertainty. I am therefore left with using the short-run information-hoping that long-run uncertainty can be proxied by (linear functions of) short-term uncertainty.

The Federal Reserve Bank of Cleveland (2008) calculates an adjusted break-even inflation by adding a real liquidity premium $(L P R)$ - that is, as $i-(r-L P R)$. The idea is that the observed real interest rate $(r)$ needs to be adjusted down to correct for the liquidity risk premium of the real bonds. To construct this real liquidity premium (which is not directly observable), Federal Reserve Bank of Cleveland (2008) argues that it is likely 
to be strongly related to the yield difference between less and more liquid ("off-the-run" and "on the run") 10-year nominal Treasury bonds (denoted LPO below). The functional form used is

$$
L P R=-0.948+12.71 L P O-20.9 L P O^{2} .
$$

The negative constant is meant to capture a constant inflation risk premium of the nominal bond, so $L P R$ is more than just a real liquidity premium. Figure 1 shows the time series of $L P O$, the functional form of equation (4) with markers for the quartiles of the sample, and the resulting time series of $L P R$. The first and third subfigure illustrate that the liquidity premia peak around 1999-2000 and 2002-2003 and are markedly low 2005-2007. The second subfigure shows that the functional form of (4) is effectively linear with a slope of approximately 3.5, except for some very rare cases (the peak in 1999). The publication of the LPR was discontinued in the autumn 2008, which forces my sample to end in 2008Q2. ${ }^{3}$

I use $L P O$ as a regressor together with my proxies for macro economic uncertainty. In practice, this means that I try to replace the constant inflation risk premium in (4) with time-varying proxies of inflation risk.

Based on these considerations, the main empirical specification of the current paper is to regress the total premium as

$$
i-r-\mathrm{E} \pi \text { on }\left[\begin{array}{c}
\text { individual uncertainty } \\
\text { disagreement }
\end{array}\right] \text { about }\left[\begin{array}{c}
\text { inflation } \\
\text { real growth }
\end{array}\right] \text { and LPO. }
$$

Notice that $L P O$ enters the regression to capture the real liquidity premium, so I expect a negative coefficient. (The nominal interest rates used here are based on highly liquid instruments.)

If the nominal interest rate and inflation expectations are non-stationary, but cointegrated (with a coefficient of unity), then (5) is expressed in terms of stationary variables (assuming, of course, that the real interest rate is stationary).

To summarize, a consumption-based asset pricing model (3) with heterogenous beliefs suggests that the nominal interest rate should be driven by the terms in (5). The

\footnotetext{
${ }^{3}$ On 31 October 2008 Federal Reserve Bank of Cleveland (2008) states: "We have discontinued the liquidity-adjusted TIPS expected inflation estimates for the time being. The adjustment was designed for more normal liquidity premiums. We believe that the extreme rush to liquidity is affecting the accuracy of the estimates."
} 
coefficients are essentially an empirical issue as they depend on several unknown parameters: the risk aversion coefficient, the importance of disagreement and the properties of the approximations. The rest of this section discusses how the variables in the regression are constructed.

\subsection{Construction of Variables Used in the Regressions}

The 3- and 10-year nominal and real interest rates as well as the (median) inflation expectations are shown in Figure 2. There are substantial movements in all three variables, except the 10-year inflation expectations which are virtually flat after 1999. I choose to focus on the horizons of 3 and 10 years: the real rates for shorter maturities are less reliable - and it can be shown that the regression results for maturities between 3 and 10 years are well approximated by straightforward interpolation.

The 3- and 10-year inflation expectations are constructed from the median (across forecasters) CPI inflation forecasts-by linear interpolation of the forecasts for the next calendar year and for the next 10 years.

The upper panel of Figure 3 compares the break-even inflation expectation $(i-r)$ to the survey forecasts of inflation $(\mathrm{E} \pi)$, and the lower panel shows the difference between them-that is, the "total premium" $(i-r-\mathrm{E} \pi)$. There are marked cyclical swings in the total premia and they are strongly correlated across maturities with a peak in 1997 , 2000, 2004-8 and very low values in 1999 and 2002-3. As discussed earlier, the approach of this paper is to investigate if the movements of the total premia can be explained by macroeconomic uncertainty and a liquidity premium.

The uncertainty of deflator inflation and output growth is estimated by fitting distributions to the individual histograms in the SPF. The estimation procedure is as follows. If only one bin is used (the respondent puts $100 \%$ of the probability on one of the prespecified bins), then I assume a triangular distribution within that bin. If two or more bins are used, then a normal distribution is estimated (a mean and a variance) by minimizing the sum of the squared deviations of the theoretical from the observed probabilities. (See Giordani and Söderlind (2003) for an early application and García and Manzanares (2007) for a critique of the least squares criterion.)

There is a lot of cross-sectional (across forecasters) dispersion in the fitted values from the individual histograms - some of which appears to be caused by typos and other data errors. To get robust estimates of the average individual uncertainty, I use the cross- 

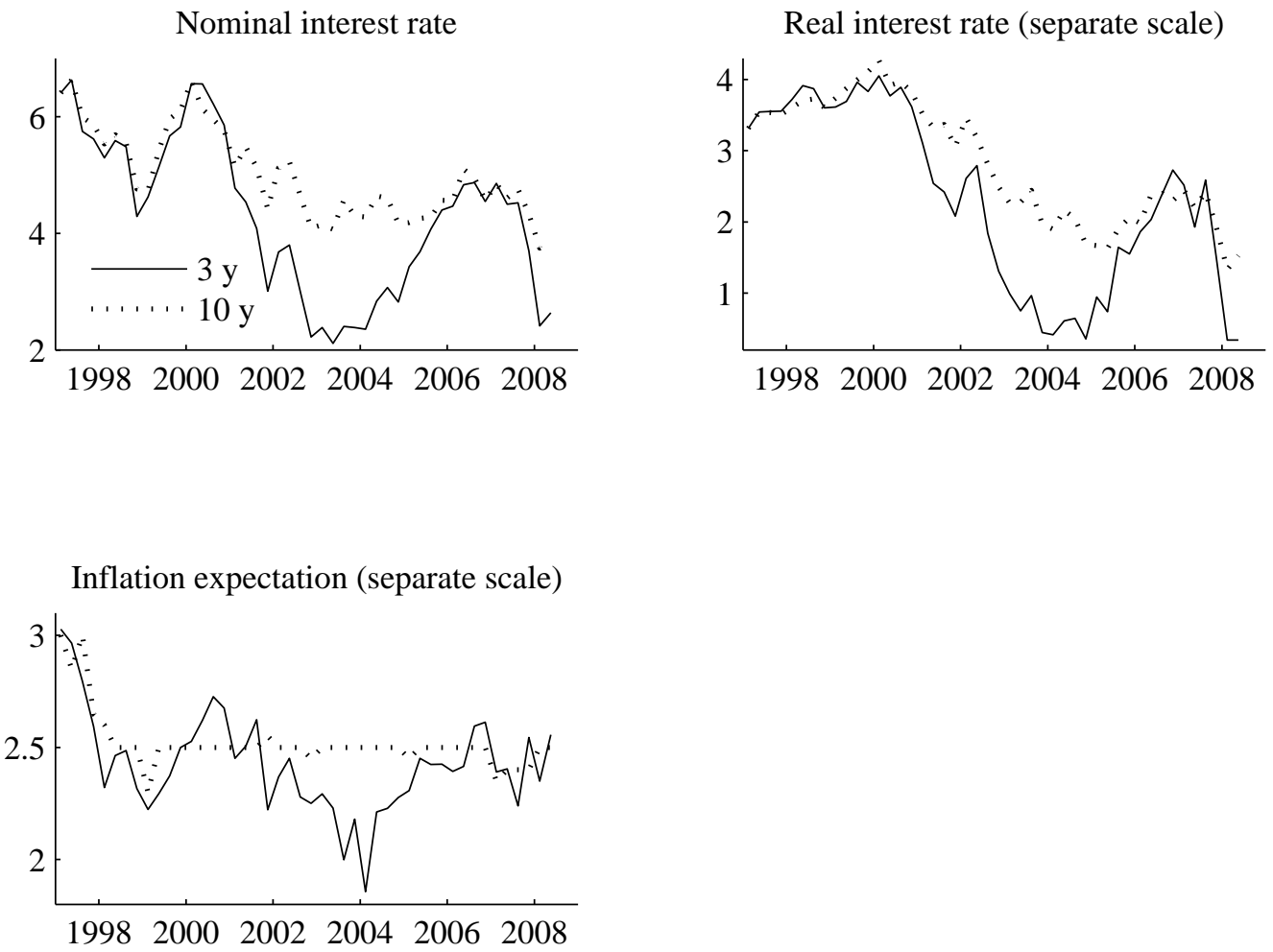

Figure 2: Interest rates (nominal and real) and inflation expectations. This figure shows estimated nominal and real zero coupon rates from McCulloch's homepage, as well as inflation expectations from the SPF.

sectional trimmed mean ( $20 \%$ trimming from both bottom and top) of the individual standard deviations. (Using the median gives very similar results and using the mean produces fairly similar, but more erratic results.)

The probability distributions (histograms) of real output growth and inflation are for year-on-year data (the value in a calendar year divided by the value in the previous calendar year, minus one). This means that the forecasting horizon varies across the sample: the current (next) year forecast made in Q1 has a four (eight) quarter horizon, the forecast made in Q2 has a three (seven) quarter horizon and so forth. The estimated uncertainty therefore has clear seasonality - as the effective forecasting horizon decreases over the calendar year. The rest of the paper will therefore focus on results where all series are 4-quarter moving averages (using an X12 approach gives similar results).

Disagreement (about inflation and real growth) is measured by the inter-quartile range 
Inflation "expectations", 3 y

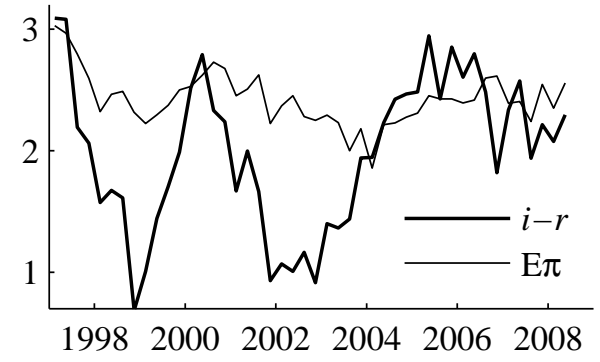

Inflation "expectations", $10 \mathrm{y}$

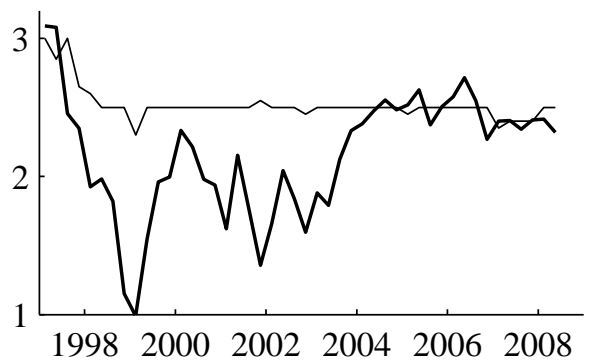

Total premium $(i-r-\mathrm{E} \pi)$

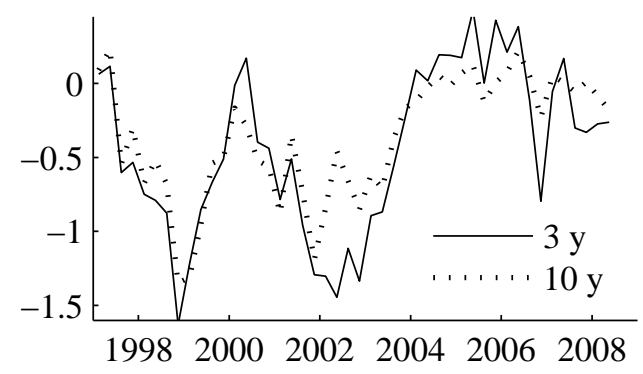

Figure 3: Interest rates (nominal and real) and inflation expectations. This figure shows various combinations of estimated nominal and real zero coupon rates from McCulloch, as well as inflation expectations from the SPF.

(divided by 1.35) of the individual point forecasts. This is a robust estimator of the cross-sectional dispersion - and would coincide with the standard deviation if the crosssectional distribution were Gaussian. (Using a cross-sectional standard error produces a very erratic time series, due to occasional strange forecasts.) Similar to the estimates of uncertainty, there is a distinct seasonal pattern in disagreement (driven by the timevariation in the forecasting horizon).

The upper panel of Figure 4 shows uncertainty (estimated from the histograms) about inflation and real growth for the current and next calendar year. The lower panel shows disagreement (estimated from the cross-sectional dispersion of the point forecasts) about the same variables. There are significant movements in these data series, with some interesting patterns. First, the results for year 1 and year 2 convey virtually the same information. The uncertainty about the next calendar year is of course higher, but the 

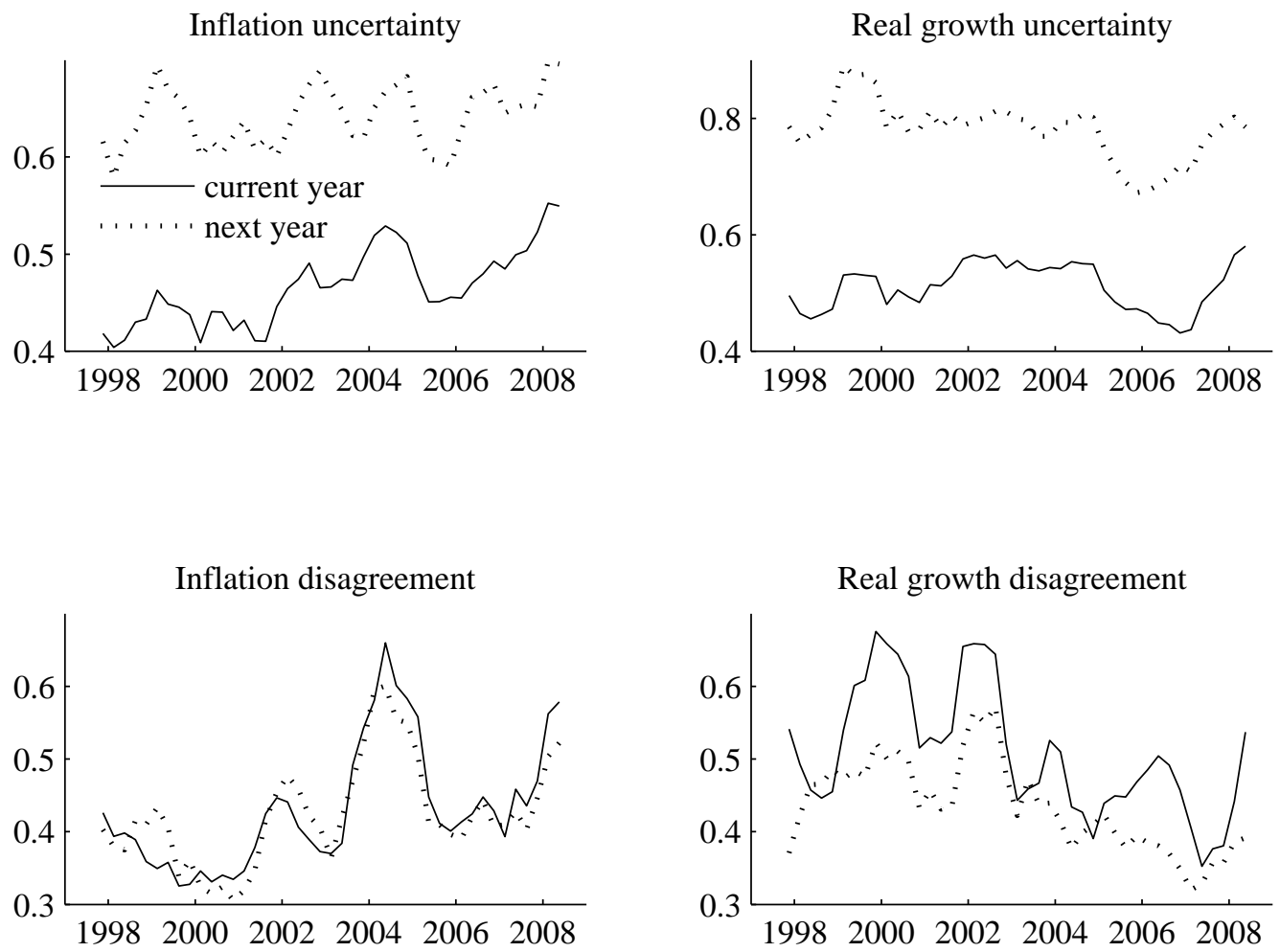

Figure 4: Uncertainty and disagreement about inflation and real growth. Uncertainty is estimated by the trimmed ( $20 \%$ at both ends) cross-sectional mean of the individual standard deviations of year-on-year GDP deflator inflation and output growth. The individual standard deviations are estimated from the individual SPF histograms. Disagreement is estimated by the inter-quartile range (divided by 1.35) of the individual point forecasts of $\mathrm{CPI}$ and real growth. All data is in the form of 4-quarter moving averages.

correlation of year 1 and 2 is very strong (around 0.7 for both variables). In addition, inflation disagreement is almost the same for both years and the two series for real growth disagreement are also strongly correlated (around 0.8). Second, inflation uncertainty and disagreement are strongly correlated (around 0.7). Third, real growth uncertainty and disagreement are less correlated (around 0.3) and the disagreement series looks very jumpy. Fourth, inflation and real growth uncertainty are only mildly correlated (around 0.4). These features will be important for the empirical results reported in the next section. 

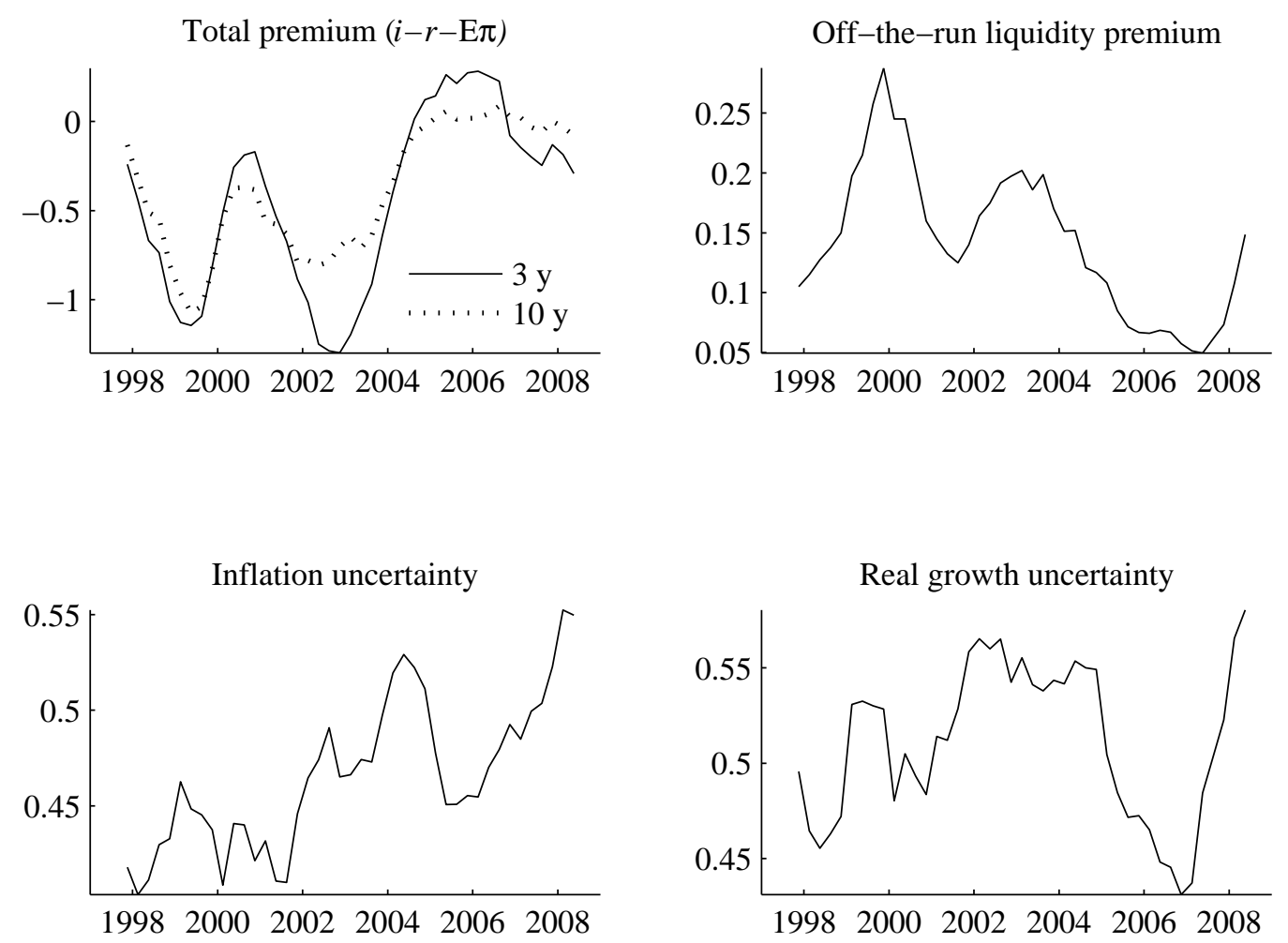

Figure 5: Total premium and the key regressors. This figure shows the total premium $(i-r-\mathrm{E} \pi)$, liquidity premium, inflation uncertainty and real growth uncertainty. All data is in the form of 4-quarter moving averages.

\section{Empirical Results}

This section reports the empirical results for quarterly data from 1997Q1 to 2008Q2 for the 3- and 10-year maturities. It can be shown that results for intermediate maturities are well approximated by linear interpolation. All data is in the form of 4-quarter moving averages - as a simple way to handle the strong seasonality in the survey data on uncertainty and disagreement (caused by the time variation in the effective forecasting horizon). Regressions on seasonally adjusted data give very similar results, but somewhat lower $R^{2}$ values.

Figure 5 shows the total premium $(i-r-\mathrm{E} \pi)$ and some of the key regressors. Only regressor values for year 1 are shown and used in the subsequent analysis, since the data for year 2 contributes very little extra information (compare Figure 4) and since the data 
for year 1 appears to be somewhat more reliable (in particular, it has fewer suspicious histograms).

\begin{tabular}{lcccc} 
& $(1)$ & $(2)$ & $(3)$ & $(4)$ \\
\hline LPO & -4.61 & & & \\
& $(-6.03)$ & & & \\
$\sigma(\Delta y)$ & & -3.75 & & \\
& & $(-2.15)$ & & \\
$\operatorname{Dis}(\Delta c)$ & & & -2.57 & \\
& & & $(-5.84)$ & \\
VIX & & & & -0.06 \\
& & & & $(-9.32)$ \\
constant & 0.27 & 1.53 & 0.92 & 0.84 \\
& $(2.74)$ & $(1.76)$ & $(3.66)$ & $(8.02)$ \\
R2 & 0.63 & 0.18 & 0.40 & 0.73 \\
obs & 43.00 & 43.00 & 43.00 & 43.00 \\
\hline
\end{tabular}

Table 1: Regression results, total premium for the 10-year maturity. The table shows regression coefficients and t-statistics (in parentheses) for quarterly data 1997Q1-2008Q2. The dependent variable is the nominal interest rate minus the real interest rate and minus expected inflation (10-year horizon). The t-statistics are based on a Newey-West estimator with 4 lags.

\subsection{Explaining the Observed Total Premium with the Liquidity Premium}

The potential of the off-the-run liquidity premium to fit the total premium $(i-r-\mathrm{E} \pi)$ is clear from the upper panel of Figure 5: the total premium and the off-the-run liquidity premium appear to be strongly negatively correlated. This is consistent with the interpretation (by Federal Reserve Bank of Cleveland (2008)) that the off-the-run liquidity premium is a reasonable proxy for the real liquidity premium - and should therefore be negatively related to the total premium.

This is verified by the first column of Table 1 which reports results from an OLS regression of the 10-year total premium on the off-the-run liquidity premium (and a constant). The t-statistics (in parentheses) are based on a Newey-West estimator of the covariance matrix with 4 lags, to account for the autocorrelation that is potentially induced by using 4-quarter moving averages. The slope coefficient is significantly negative, with 
a value (-4.6) that fits well with the slope of the functional form of (4) as previously illustrated in Figure 1, and the $R^{2}$ is high. This confirms the usefulness of the off-the-run liquidity premium.

It can be shown that the off-the-run liquidity premium is correlated with several of the other potential regressors. In particular, it is strongly correlated with real growth uncertainty and disagreement (correlation coefficients of $0.50-0.75$ ). It is also strongly correlated with CBOE's volatility index VIX (0.80), which is an average of implied volatilities from stock options - and should therefore provide a summary measure of the market's belief about future stock market volatility. In contrast, the off-the-run liquidity premium is only weakly (and negatively) correlated with inflation uncertainty and disagreement. Therefore, it is reasonable to believe that the off-the-run premium, uncertainty and disagreement about real growth and the VIX all are proxies of the general level of liquidity premia on the bond markets, while inflation uncertainty and disagreement represent something else.

Columns 2-4 of Table 1 report results from regressing the total premium on these other proxies for the liquidity premium (one at a time). All have negatives signs and are significant-and it is hard to tell which of them is the best proxy (for instance, VIX actually gives a higher $R^{2}$ than the off-the-run liquidity premium).

However, the off-the-run premium is by now well established by the Federal Reserve Bank of Cleveland (2008) and it has the advantage of focusing on the liquidity on the Treasury bond market, rather than general financial uncertainty. I will therefore keep it in the subsequent regressions-but add other variables.

\subsection{Adding Proxies for Macroeconomic Uncertainty/Disagreement}

Table 2 reports results from a number of regressions of the 10-year total premium based on model (5). The first column shows that both inflation uncertainty and disagreement have significantly positive effects on the total premium, output growth uncertainty has a significantly negative effect while real growth disagreement has a small and insignificant coefficient. The latter variable is dropped in the second column and all further regressions (it is almost invariably insignificant in these and other regressions). The off-the-run liquidity premium still has a negative effect, although it is now only borderline significant. The $R^{2}$ is 0.78 , which is significantly higher (at the $5 \%$ level) than the 0.63 obtained from using only the liquidity premium (see Table 1). 
The remaining columns in Table 2 report results when some further variables are dropped. In short, the results are that inflation uncertainty and disagreement are close substitutes (columns 3 and 4), that dropping output uncertainty lowers the $R^{2}$ a bit (column 5), but that dropping the liquidity premium does less so (column 6).

One interpretation of the results in Table 2 is that $(i)$ uncertainty/disagreement about inflation induces an "inflation risk premium" and (ii) output growth uncertainty and the off-the-run liquidity premium together capture the liquidity premium on real bonds (similar to the finding in Table 1).

\begin{tabular}{lcccccc} 
& $(1)$ & $(2)$ & $(3)$ & $(4)$ & $(5)$ & $(6)$ \\
\hline$\sigma(\pi)$ & 2.57 & 2.46 & & 4.09 & 2.02 & 3.27 \\
& $(2.53)$ & $(2.58)$ & & $(4.20)$ & $(2.69)$ & $(3.13)$ \\
$\operatorname{Dis}(\pi)$ & 1.51 & 1.48 & 2.09 & & & 2.13 \\
& $(3.35)$ & $(3.47)$ & $(4.46)$ & & & $(3.56)$ \\
$\sigma(\Delta y)$ & -4.49 & -4.38 & -3.56 & -3.32 & & -6.71 \\
& $(-2.97)$ & $(-2.88)$ & $(-2.08)$ & $(-2.04)$ & & $(-9.31)$ \\
$\operatorname{Dis}(\Delta c)$ & 0.19 & & & & & \\
LPO & $(0.30)$ & & & & & \\
& -2.17 & -2.04 & -2.42 & -2.85 & -4.28 & \\
constant & $(-1.88)$ & $(-1.90)$ & $(-2.04)$ & $(-2.58)$ & $(-5.19)$ & \\
& 0.27 & 0.36 & 0.88 & -0.19 & -0.72 & 0.60 \\
R2 & $(0.39)$ & $(0.69)$ & $(1.38)$ & $(-0.38)$ & $(-2.05)$ & $(1.08)$ \\
obs & 0.78 & 0.78 & 0.75 & 0.73 & 0.67 & 0.73 \\
& 43.00 & 43.00 & 43.00 & 43.00 & 43.00 & 43.00 \\
\hline
\end{tabular}

Table 2: Regression results, total premium for the 10-year maturity. The table shows regression coefficients and t-statistics (in parentheses) for quarterly data 1997Q1-2008Q2. The dependent variable is the nominal interest rate minus the real interest rate and minus expected inflation (10-year horizon). The t-statistics are based on a Newey-West estimator with 4 lags.

The results for the 3-year horizon in Table 3 are similar, with a few exceptions. First, inflation uncertainty is never significant if inflation disagreement is included in the regression-highlighting their substitutability. Second, the liquidity premium is even less significant than before. Third, the $R^{2}$ values are generally lower. Still, the overall results are the same as for the 10-year horizon, but perhaps somewhat weaker.

To illustrate the economic importance of the results, consider (for example) the re- 


\begin{tabular}{lcccccc} 
& $(1)$ & $(2)$ & $(3)$ & $(4)$ & $(5)$ & $(6)$ \\
\hline$\sigma(\pi)$ & 1.06 & 0.51 & & 3.61 & 0.42 & 1.23 \\
& $(0.49)$ & $(0.29)$ & & $(2.31)$ & $(0.27)$ & $(0.68)$ \\
$\operatorname{Dis}(\pi)$ & 2.98 & 2.82 & 2.94 & & & 3.39 \\
& $(3.64)$ & $(3.16)$ & $(4.19)$ & & & $(3.80)$ \\
$\sigma(\Delta y)$ & -7.66 & -7.14 & -6.97 & -5.12 & & -9.22 \\
& $(-3.10)$ & $(-2.87)$ & $(-2.71)$ & $(-1.89)$ & & $(-5.52)$ \\
$\operatorname{Dis}(\Delta c)$ & 0.95 & & & & & \\
& $(0.90)$ & & & & & \\
LPO & -2.43 & -1.82 & -1.90 & -3.35 & -5.56 & \\
& $(-1.31)$ & $(-1.04)$ & $(-1.10)$ & $(-1.87)$ & $(-3.36)$ & \\
constant & 1.54 & 2.00 & 2.11 & 0.96 & 0.14 & 2.22 \\
& $(1.02)$ & $(1.66)$ & $(1.96)$ & $(0.88)$ & $(0.18)$ & $(1.87)$ \\
R2 & 0.65 & 0.63 & 0.63 & 0.55 & 0.48 & 0.61 \\
obs & 43.00 & 43.00 & 43.00 & 43.00 & 43.00 & 43.00 \\
\hline
\end{tabular}

Table 3: Regression results, total premium for the 3-year maturity. The table shows regression coefficients and t-statistics (in parentheses) for quarterly data 1997Q1-2008Q2. The dependent variable is the nominal interest rate minus the real interest rate and minus expected inflation (3-year horizon). The t-statistics are based on a Newey-West estimator with 4 lags.

gression results for the 10-year maturity in column 4 of Table 2, which can be written (disregarding the residual)

$$
\begin{aligned}
i-r-\mathrm{E} \pi=\mu-L P R+I P, \text { with } \\
\qquad\left\{\begin{array}{l}
\mu=-0.38 \\
L P R=3.32[\sigma(y)-\mathrm{E} \sigma(y)]+2.85[L P O-\mathrm{E} L P O] \\
I P=4.09[\sigma(\pi)-\mathrm{E} \sigma(\pi)] .
\end{array}\right.
\end{aligned}
$$

Compared to the table, all means are moved to the intercept $(\mu)$, which therefore is the average total premium. I also interpret the inflation uncertainty term as the (demeaned) inflation risk premium of the nominal interest rate $(I P)$, and the real growth uncertainty and off-the-run liquidity premium as capturing the (demeaned) liquidity premium of the real interest rate $(L P R)$. The motivation for rewriting the equation in terms of demeaned variables is that the average values of the inflation and liquidity premia cannot be separately identified from the regression (only the sum of them-in the form of the intercept 
$\mu$ - - so the discussion here is focused on their movements.

Figure 6 illustrates this decomposition. The upper left subfigure shows that the fitted values capture the main movements of the total premium $(i-r-\mathrm{E} \pi)$-indeed, the $R^{2}$ is 0.73 . The upper right subfigure shows the inflation risk premium and (the negative of) the real liquidity premium. There are clear movements in both components-and they suggest the following story for the movements of the total premium. The trough in 19992000 is due to a high real liquidity premium: both output uncertainty and off-the-run liquidity premia are high then (see Figure 5). The real liquidity premium falls back over the next year (mostly because of the off-the-run liquidity premium), creating a local peak in the total premium 2001. The moderately low total premium in 2002-2004 is similar to the trough in 1999-2000 (that is, mostly driven by a high liquidity premium), except that the increase in the inflation risk premium prevents the total premium from falling very much. The very high total premium $2004-2007$ is initially driven by a low liquidity premium (in spite of a falling inflation risk premium) — and later increased further by a higher inflation risk premium. Towards the end of the sample (2008), there is a tendency for the total premium to decrease due to an increasing liquidity premium.

The lower panel of Figure 6 illustrates how these results would adjust the break-even inflation rate. The idea is based on (6) which can also be written as

$$
i-r-\mu+L P R-I P=\mathrm{E} \pi \text {. }
$$

In the lower left subfigure, I compare a mean-adjusted break-even rate that is only mean adjusted $(i-r-\mu)$ and one that incorporates also the real liquidity premium $(i-r-\mu+$ $L P R)$. The mean-adjusted rate is clearly just a vertical shift of the unadjusted break-even $(i-r)$ previously shown in Figure 3. In contrast, adding the real liquidity premium makes the break-even inflation rate smoother: the troughs and peaks are less dramatic-making the curve look more similar to the (very flat) survey inflation expectations (previously shown in Figure 3). In the lower right subfigure, also the effect of the inflation risk premium $(I P)$ is subtracted. This increases the break-even inflation rate 1999-2002 (since the inflation risk premium is low) and decreases it 2003-2005 and 2007-2008 (when the inflation risk premium is high). 

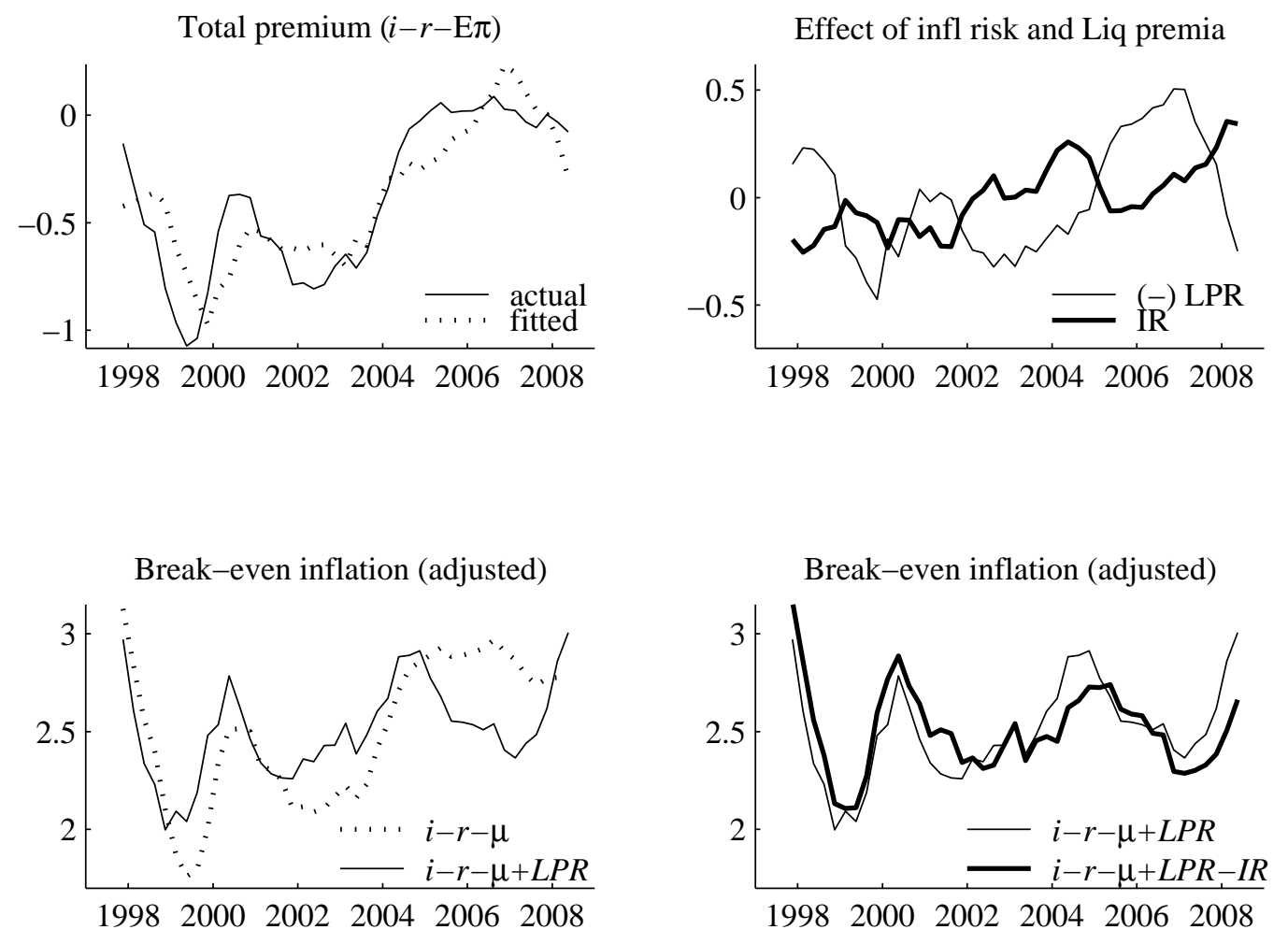

Figure 6: Total premium and the effect of key regressors (demeaned), 10-year maturity. This figure shows the total premium $(i-r-\mathrm{E} \pi)$, the (demeaned) inflation risk premium and (the negative of) the real liquidity premium defined in (6, and various adjustments of the break-even inflation rate defined in (7. All data is in the form of 4-quarter moving averages.

\section{Concluding Remarks}

This paper tries to explain the observed "total premium" (the difference between nominal and real interest rates, minus survey data on inflation expectations) by the nominal off-the-run liquidity premium as well as survey data on inflation and output uncertainty/disagreement. It is found that these variables are statistically and economically significant. Inflation uncertainty and uncertainty seem to capture an inflation risk premium, while the nominal off-the-run liquidity premium and real growth uncertainty together capture the real liquidity premium. This leads to important adjustments of the break-even inflation rate. 
There are several caveats, however. The sample is short, has only a quarterly frequency and must be seasonally adjusted. The reasons are (respectively) that data on real interest rates starts only in 1997Q1, the survey data is quarterly and it has a forecasting horizon that varies over the calendar year.

In spite of these limitations, it is interesting to study a modern Fisher equation where we have at least proxies for the terms that asset pricing theory suggests. The empirical results are encouraging since they suggest plausible effects of macroeconomic uncertainty on nominal interest rates.

I hope that this paper contributes to the understanding of the economic factors behind the inflation risk and liquidity premia. It could also be of help to central bank staff and others who need to adjust break-even inflation rates. Further research might be able to find high-frequency proxies for inflation and output uncertainty/disagreement and thereby further improve current practices. 


\section{References}

Anderson, E. W., E. Ghysel, and J. L. Juergens, 2005, "Do heterogenous beliefs matter for asset pricing," Review of Financial Studies, 18, 875-924.

Carlstrom, C. T., and T. S. Fuerst, 2004, "Expected inflation and TIPS," Federal Reserve Bank of Cleveland Economic Commentary, November, 1-4.

Chen, R.-R., B. Liu, and X. Cheng, 2005, "Inflation, Fisher equation, and the term structure of inflation risk premia: theory and evidence from TIPS," SSRN eLibrary.

Croushore, D., 1993, "Introducing: the Survey of Professional Forecasters," Federal Reserve Bank of Philadelphia Business Review, pp. 3-13.

D’Amico, S., D. H. Kim, and M. Wei, 2008, "Tips from TIPS: the informational content of Treasury Inflation-Protected Security prices,” Working paper 248, Bank for International Settlements.

David, A., 2008, "Heterogeneous beliefs, speculation, and the equity premium," Journal of Finance, Volume 63, 41-83.

Federal Reserve Bank of Cleveland, 2008, "TIPS expected inflation estimates," http://www.clevelandfed.org/research/data/tips/index.cfm.

Federal Reserve Bank of Philadelphia, 2008, "Survey of Professional Forecasters," http://www.philadelphiafed.org/econ/spf/index.cfm.

García, J., and A. Manzanares, 2007, "What can probability forecasts tell us about inflation risks?," Working Paper 825, European Central Bank.

Giordani, P., and P. Söderlind, 2003, "Inflation forecast uncertainty," European Economic Review, 47, 1037-1059.

Lahiri, K., C. Teigland, and M. Zaporowski, 1988, "Interest rates and the subjective probability distribution of inflation forecasts," Journal of Money, Credit, and Banking, 20, 233-248.

McCulloch, J. H., 2008, "The US real term structure of interest rates," http://economics.sbs.ohio-state.edu/jhm/ts/ts.html. 
Reschreither, A., 2004, "Conditional funding costs of inflation-indexed and conventional government bonds," Journal of Banking and Finance, 28, 1299-1318.

Shen, P., 2006, "Liquidity risk premia and breakeven inflation rates," Federal Reserve Bank of Kansas Economic Review, 2nd Quarter, 29-54.

Söderlind, P., 2008, "Why disagreement may not matter (much) for asset prices," Finance Research Letters, forthcoming. 


\section{Swiss National Bank Working Papers published since 2004:}

2004-1 Samuel Reynard: Financial Market Participation and the Apparent Instability of Money Demand

2004-2 Urs W. Birchler and Diana Hancock: What Does the Yield on Subordinated Bank Debt Measure?

2005-1 Hasan Bakhshi, Hashmat Khan and Barbara Rudolf: The Phillips curve under state-dependent pricing

2005-2 Andreas M. Fischer: On the Inadequacy of Newswire Reports for Empirical Research on Foreign Exchange Interventions

2006-1 Andreas M. Fischer: Measuring Income Elasticity for Swiss Money Demand: What do the Cantons say about Financial Innovation?

2006-2 Charlotte Christiansen and Angelo Ranaldo: Realized Bond-Stock Correlation: Macroeconomic Announcement Effects

2006-3 Martin Brown and Christian Zehnder: Credit Reporting, Relationship Banking, and Loan Repayment

2006-4 Hansjörg Lehmann and Michael Manz: The Exposure of Swiss Banks to Macroeconomic Shocks - an Empirical Investigation

2006-5 Katrin Assenmacher-Wesche and Stefan Gerlach: Money Growth, Output Gaps and Inflation at Low and High Frequency: Spectral Estimates for Switzerland

2006-6 Marlene Amstad and Andreas M. Fischer: Time-Varying Pass-Through from Import Prices to Consumer Prices: Evidence from an Event Study with Real-Time Data

2006-7 Samuel Reynard: Money and the Great Disinflation

2006-8 Urs W. Birchler and Matteo Facchinetti: Can bank supervisors rely on market data? A critical assessment from a Swiss perspective

2006-9 Petra Gerlach-Kristen: A Two-Pillar Phillips Curve for Switzerland

2006-10 Kevin J. Fox and Mathias Zurlinden: On Understanding Sources of Growth and Output Gaps for Switzerland

2006-11 Angelo Ranaldo: Intraday Market Dynamics Around Public Information Arrivals

2007-1 Andreas M. Fischer, Gulzina Isakova and Ulan Termechikov: Do FX traders in Bishkek have similar perceptions to their London colleagues? Survey evidence of market practitioners' views 
2007-2 Ibrahim Chowdhury and Andreas Schabert: Federal Reserve Policy viewed through a Money Supply Lens

2007-3 Angelo Ranaldo: Segmentation and Time-of-Day Patterns in Foreign Exchange Markets

2007-4 Jürg M. Blum: Why `Basel II’ May Need a Leverage Ratio Restriction

2007-5 Samuel Reynard: Maintaining Low Inflation: Money, Interest Rates, and Policy Stance

2007-6 Rina Rosenblatt-Wisch: Loss Aversion in Aggregate Macroeconomic Time Series

2007-7 Martin Brown, Maria Rueda Maurer, Tamara Pak and Nurlanbek Tynaev: Banking Sector Reform and Interest Rates in Transition Economies: Bank-Level Evidence from Kyrgyzstan

2007-8 Hans-Jürg Büttler: An Orthogonal Polynomial Approach to Estimate the Term Structure of Interest Rates

2007-9 Raphael Auer: The Colonial Origins Of Comparative Development: Comment. A Solution to the Settler Mortality Debate

2007-10 Franziska Bignasca and Enzo Rossi: Applying the Hirose-Kamada filter to Swiss data: Output gap and exchange rate pass-through estimates

2007-11 Angelo Ranaldo and Enzo Rossi: The reaction of asset markets to Swiss National Bank communication

2007-12 Lukas Burkhard and Andreas M. Fischer: Communicating Policy Options at the Zero Bound

2007-13 Katrin Assenmacher-Wesche, Stefan Gerlach, and Toshitaka Sekine: Monetary Factors and Inflation in Japan

2007-14 Jean-Marc Natal and Nicolas Stoffels: Globalization, markups and the natural rate of interest

2007-15 Martin Brown, Tullio Jappelli and Marco Pagano: Information Sharing and Credit: Firm-Level Evidence from Transition Countries

2007-16 Andreas M. Fischer, Matthias Lutz and Manuel Wälti: Who Prices Locally? Survey Evidence of Swiss Exporters

2007-17 Angelo Ranaldo and Paul Söderlind: Safe Haven Currencies 
2008-1 Martin Brown and Christian Zehnder: The Emergence of Information Sharing in Credit Markets

2008-2 Yvan Lengwiler and Carlos Lenz: Intelligible Factors for the Yield Curve

2008-3 Katrin Assenmacher-Wesche and M. Hashem Pesaran: Forecasting the Swiss Economy Using VECX* Models: An Exercise in Forecast Combination Across Models and Observation Windows

2008-4 Maria Clara Rueda Maurer: Foreign bank entry, institutional development and credit access: firm-level evidence from 22 transition countries

2008-5 Marlene Amstad and Andreas M. Fischer: Are Weekly Inflation Forecasts Informative?

2008-6 Raphael Auer and Thomas Chaney: Cost Pass Through in a Competitive Model of Pricing-to-Market

2008-7 Martin Brown, Armin Falk and Ernst Fehr: Competition and Relational Contracts: The Role of Unemployment as a Disciplinary Device

2008-8 Raphael Auer: The Colonial and Geographic Origins of Comparative Development

2008-9 Andreas M. Fischer and Angelo Ranaldo: Does FOMC News Increase Global FX Trading?

2008-10 Charlotte Christiansen and Angelo Ranaldo: Extreme Coexceedances in New EU Member States' Stock Markets

2008-11 Barbara Rudolf and Mathias Zurlinden: Measuring capital stocks and capital services in Switzerland

2008-12 Philip Sauré: How to Use Industrial Policy to Sustain Trade Agreements

2008-13 Thomas Bolli and Mathias Zurlinden: Measuring growth of labour quality and the quality-adjusted unemployment rate in Switzerland

2008-14 Samuel Reynard: What Drives the Swiss Franc?

2008-15 Daniel Kaufmann: Price-Setting Behaviour in Switzerland - Evidence from CPI Micro Data

2008-16 Katrin Assenmacher-Wesche and Stefan Gerlach: Financial Structure and the Impact of Monetary Policy on Asset Prices

2008-17 Ernst Fehr, Martin Brown and Christian Zehnder: On Reputation: A Microfoundation of Contract Enforcement and Price Rigidity 
2008-18 Raphael Auer and Andreas M. Fischer: The Effect of Low-Wage Import Competition on U.S. Inflationary Pressure

2008-19 Christian Beer, Steven Ongena and Marcel Peter: Borrowing in Foreign Currency: Austrian Households as Carry Traders

2009-1 Thomas Bolli and Mathias Zurlinden: Measurement of labor quality growth caused by unobservable characteristics

2009-2 Martin Brown, Steven Ongena and Pinar Yeșin: Foreign Currency Borrowing by Small Firms

2009-3 Matteo Bonato, Massimiliano Caporin and Angelo Ranaldo: Forecasting realized (co)variances with a block structure Wishart autoregressive model

2009-4 Paul Söderlind: Inflation Risk Premia and Survey Evidence on Macroeconomic Uncertainty 
Swiss National Bank Working Papers are also available at www.snb.ch, section Publications/Research Subscriptions or individual issues can be ordered at Swiss National Bank, Fraumünsterstrasse 8, CH-8022 Zurich, fax+41 4463181 14, E-mail library@snb.ch 